Research Article

\title{
Wind-Induced Response of Inclined and Yawed Ice-Accreted Stay Cable Models
}

\author{
Songyu Cao, ${ }^{1}$ Himan Hojat Jalali $\mathbb{D}^{2}{ }^{2}$ and Elena Dragomirescu $\mathbb{D D}^{3}$ \\ ${ }^{1}$ Key Laboratory of Transportation Tunnel Engineering, Ministry of Education, Southwest Jiaotong University, Chengdu 610031, \\ Sichuan, China \\ ${ }^{2}$ Civil Engineering Department, University of Texas at Arlington, 425 Nedderman Hall, 416 Yates St., Arlington, TX 76019, USA \\ ${ }^{3}$ Faculty of Engineering, University of Ottawa, 161 Louis Pasteur, Ottawa, ON K1N 6N5, Canada \\ Correspondence should be addressed to Elena Dragomirescu; elndrag@uottawa.ca
}

Received 23 March 2018; Revised 1 August 2018; Accepted 5 September 2018; Published 9 October 2018

Academic Editor: Tai Thai

Copyright (C) 2018 Songyu Cao et al. This is an open access article distributed under the Creative Commons Attribution License, which permits unrestricted use, distribution, and reproduction in any medium, provided the original work is properly cited.

\begin{abstract}
During the past decades, wind-induced vibrations of bridge stay cables were reported to occur under various incipient conditions. The ice formation on stay cables is one of these conditions, which causes the ice-accreted stay cables to alter their cross section geometry, thus modifying their aerodynamic characteristics. Wind tunnel tests and several CFD simulations were performed for ice-accreted inclined bridge stay cables with two ice-accretion profiles dimensions, $0.5 \mathrm{D}$ and $1 \mathrm{D}$, where $\mathrm{D}$ is the diameter of the cable. Wind-induced vibrations were analyzed experimentally for cable models with yaw inclination angles of $0^{\circ}, 30^{\circ}$, and $60^{\circ}$ and vertical inclination angles of $0^{\circ}$ and $15^{\circ}$, for Reynolds numbers of up to $4 \times 10^{5}$. The aerodynamic drag and lift coefficients of the cable models and the pressure coefficients were determined from the CFD-LES simulations. The experimental results indicated that the vertical and torsional vibrations of the ice-accreted stay cables increased with the increase of the vertical and yaw angles. Also, higher vertical and torsional vibration amplitudes were measured for the case with larger ice thickness, indicating the effect of the ice accretion profile on the cable wind-induced response.
\end{abstract}

\section{Introduction}

Cable-stayed bridges are among the most reliable and complex bridge structures, and their ability to support long spans make them an ideal solution for spanning large distances over bay or valley regions with high vehicular traffic. One of the main concerns when designing such bridges is related to the wind-induced effect on the bridge decks and towers. However, during the past decades, large-amplitude vibrations of stay cables have been reported [1-7]. These vibrations can tamper with the safety and serviceability of cable-stayed bridges and can cause unexpected fatigue failures at the cable anchor points. The causes for the stay cable vibrations vary in nature, such as rain-wind induced vibrations [5, 8], dry inclined cable galloping [2, 9-12], and high-speed vortex excitation $[8,13,14]$. Another type vibration has been reported in recent years for bridge stay cables with ice accretion, when sudden large-amplitude wind and ice accretion-induced vibrations were noticed [15-18]. For this phenomenon, the ice accumulates on the stay cable surface under freezing rain, drizzle, and wet or dry snow conditions at low temperatures. The formed ice accretion changes the cross-sectional shape of the cables, which in turn can cause aerodynamic instability [19]. Several field studies reported vibrations of stay cables in freezing conditions, which caused the ice to detach from the cables and fall on the passing vehicles. The Port Mann Bridge in Canada was temporarily closed to traffic in 2012 because of the iceaccreted cable vibrations and due to the ice falling from the stay cables causing a hazard for the traffic and people on the bridge. The Tacoma Narrows Bridge in USA was temporarily closed in 2011, due to similar hazards caused by the falling ice from the cables. Similar phenomena of ice falling from cables were reported for other bridges as well, such as the Alex Fraser Bridge in 2016, Canada; the Great Belt East Bridge, Denmark [20]; and the Severn Bridge in UK [21]. 
In an attempt to clarify the onset conditions for the iceaccreted cable vibrations, Koss and Matteoni [22] conducted a wind tunnel experiment for determining the effect of ice accretion on the aerodynamic forces, recorded for full-scale cables under $0^{\circ}$ angle of attack and Re numbers of up to $3.2 \times 10^{5}$, using the FORCE/DTU climatic wind tunnel (CWT). Also Koss et al. [23] performed an experimental investigation for determining the shape of the ice accretion formed on cables of $0.0381 \mathrm{~m}$ and $0.089 \mathrm{~m}$ in diameter, that were oriented in horizontal and vertical directions, for different exposure times and air temperatures. They classified the regions of the ice accretion profiles into the core, center area, outer area, flow-out, flow-out accumulation, and runback. The effect of the ice accretion on the aerodynamics of the vertical bridge hangers was investigated by Gjelstrup et al. [20] using static and dynamic wind tunnel tests. The aerodynamic coefficients were determined for smooth and rough surfaces of the ice-accreted cables, under smooth and turbulent wind flow conditions. Furthermore, Koss and Lund [24] presented the results of a full-scale experimental study on horizontal $160 \mathrm{~mm}$ diameter bridge cables, under wet and dry ice accretion conditions, using an innovative spray system to determine the aerodynamic coefficients and to evaluate the galloping instability using the Den Hartog criterion. Moreover, Koss et al. [25] studied the formation of ice accretion on three full-scale horizontal bridge cables with plain, helical fillet, and indented high density polyethylene (HDPE) cover, under wet and dry climatic conditions, and they concluded that gravity plays a major role in the ice profile formation on the cables under the wet icing condition. Also, this study indicated that only the cable with plain HDPE cover was susceptible to galloping instability, as per the Den Hartog criterion. Demartino et al. [19] extended this study to full-scale HDPE vertical and inclined bridge cables, and they investigated the process of ice accretion formation, the final ice shape, and the corresponding aerodynamic drag, lift, and moment coefficients for different parameters such as temperature, wind speed, and yaw angle. Using the experimental data of Demartino et al. [19], Demartino and Ricciardelli [26] modelled different galloping vibrations for one degree of freedom (1-DOF) and multiple degrees of freedom (MDOF) cables, and they analyzed the stability of bridge cables with ice accretion. Results showed that the 1-DOF models usually generate conservative results, and the use of dynamic wind tunnel experiments was recommended to confirm the results of existing theoretical models, especially for the cases where no sufficient data are available.

However, the actual wind-induced vibrations for the inclined and yawed cables in regard to the wind direction, which are very often encountered in practise, with ice accretion attached to their surface, were not specifically investigated. The current study examines the aerodynamic behavior of yawed and inclined ice-accreted stay cables. The stay cable models had vertical inclination angles of $0^{\circ}$ and $15^{\circ}$ and yaw angles of $0^{\circ}, 15^{\circ}, 30^{\circ}$, and $60^{\circ}$, while the ice accretion profile thickness were $0.5 \mathrm{D}$ and $1.0 \mathrm{D}$. Wind tunnel wind speeds between $1.5 \mathrm{~m} / \mathrm{s}$ and $15 \mathrm{~m} / \mathrm{s}$ were considered to identify the critical wind-induced cable vibrations.

\section{Experimental Set-Up and Cable Model Configuration}

The experimental program was performed in the suction wind tunnel facility of the University of Ottawa, Department of Mechanical Engineering (Figure 1(a)), which has a testing section of $61 \mathrm{~cm} \times 92 \mathrm{~cm}$, and has three openings on each side of the testing section, used for installing the models and to coordinate the necessary vertical and yaw inclination angles for the cable models. The maximum wind speed which can be achieved in the wind tunnel is $30.0 \mathrm{~m} / \mathrm{s}$; however, for the current experiment, the ice-accreted cable was tested for wind speeds of up to $15.0 \mathrm{~m} / \mathrm{s}$, corresponding to a Reynolds number of $4.0 \times 10^{5}$, considering the high amplitude vibrations developed beyond these testing conditions. The wind speed varied during the tests from $1.5 \mathrm{~m} / \mathrm{s}$ to $15.0 \mathrm{~m} / \mathrm{s}$, in steps of $1.5 \mathrm{~m} / \mathrm{s}$. The blockage ratio was determined as the total area of the model normal to the free stream velocity divided by the total area of the test section and was found to be $0.368 \times 10^{-3}$ and $0.736 \times 10^{-3}$, for the cable models with $1.0 \mathrm{~cm}$ and $2.0 \mathrm{~cm}$ ice profiles, respectively. According to West and Apelt [27], if the blockage ratio is lower than $6 \%$, for smooth cylinders with aspect ratios in the range of 4 to 10 , the Strouhal number is not affected and no correction is needed for the aerodynamic coefficients; hence, the turbulence intensity would not be a significant concern.

An important parameter which can significantly affect the wind-induced response of the cable models during the wind tunnel tests is the relative angle of attack between the wind direction and the cable axis. Therefore, the wind-cable relative angle, as defined by Cheng et al. [2], was employed in the current research, that is, $\theta=\cos ^{-1}(\cos \alpha \cos \beta)$, where $\theta, \alpha$, and $\beta$ represent the relative wind-cable angle, yaw, and vertical cable inclination angles, respectively (Figure 1(b)). To simulate the wind-induced vibrations of the cables, eight supporting springs, each of elastic constant $k=1.5 \mathrm{~N} / \mathrm{m}$, were installed symmetrically at the two ends of the cables along the vertical direction, as schematically represented in Figure 1(b). Also the position of the cable models was adjusted using the three circular openings in the wind tunnel lateral wall and by moving the entire spring support system installed outside the tunnel to adjust for different vertical and yaw angles of attack, as shown in Figures 2(a) and 2(b). For flow perpendicular to the cylinder at $0^{\circ}$ yaw, the same location openings were used for installing the model (Figure 2(c)), while for bigger yaw and vertical angles, the cable model was installed between the middle and the last opening with an elevation difference between the spring support systems (Figure 2(d)).

The cable models were scaled to $1: 45$ from the prototype bridge cable used by Cheng et al. [2] for the full-scale wind tunnel experiments conducted for the smooth surface inclined and yawed cylinders. Ice accretion profiles with a thickness of $0.5 \mathrm{D}$ and $1 \mathrm{D}$, where $\mathrm{D}$ is the diameter of the cable model, were added on one side of the cable models. These dimensions correspond, respectively, to a cable ice accretion thickness of $45 \mathrm{~cm}(0.5 \mathrm{D})$ and $90 \mathrm{~cm}$ (1D), considering the $1: 45$ scale factor. According to Koss et al. [23] exposing the cable for 1,800 seconds to precipitations under freezing conditions, the ice accretion profile thickness can 


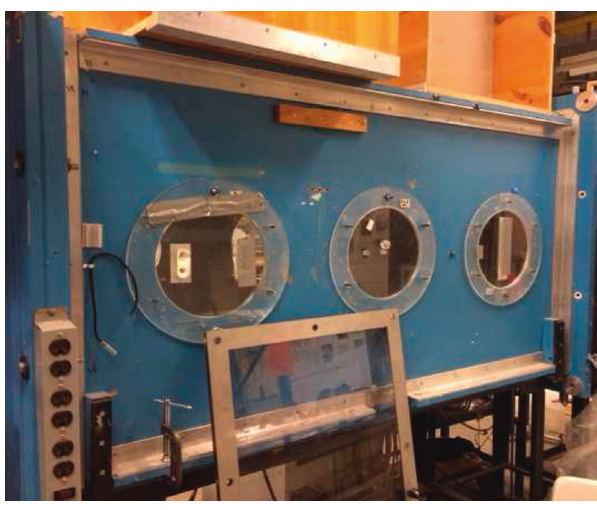

(a)

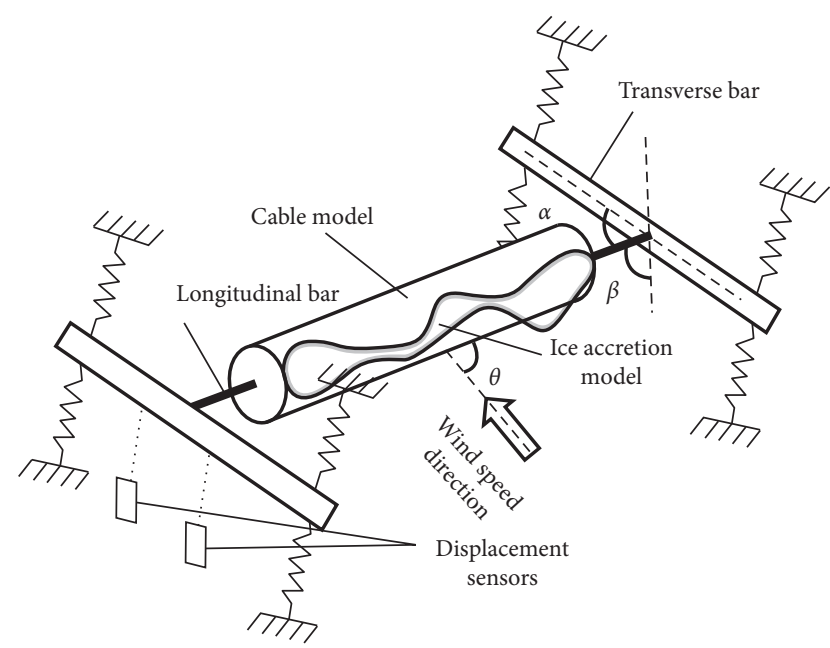

(b)

FIgURE 1: (a) Suction wind tunnel facility; (b) spring suspension system.

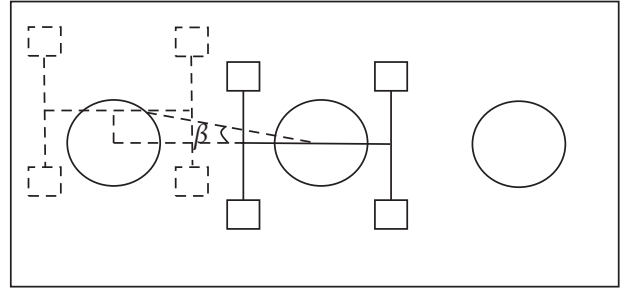

(a)

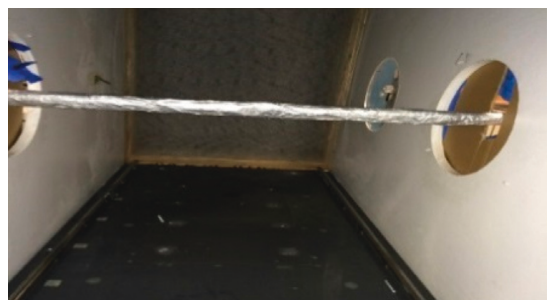

(c)

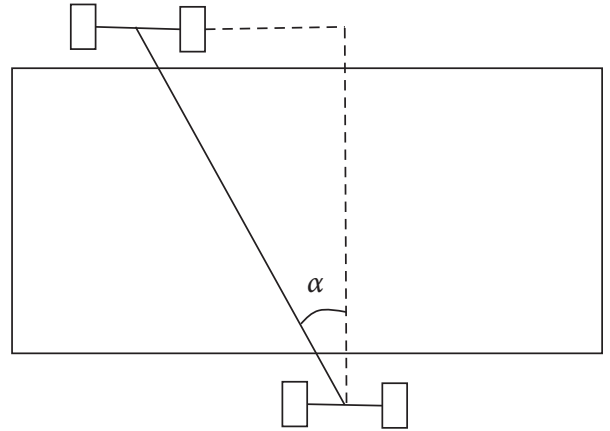

(b)

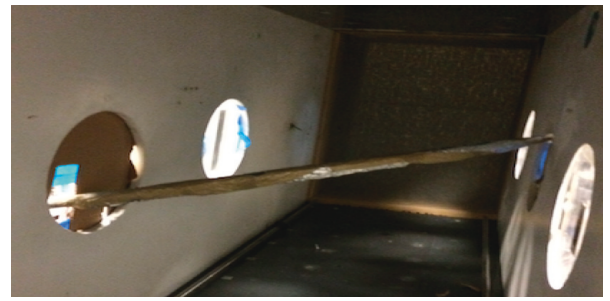

(d)

Figure 2: Cable models configuration in the wind tunnel facility: (a) front view; (b) top view; (c) $\alpha=\beta=0^{\circ}$; (d) $\alpha=60^{\circ}$ and $\beta=15^{\circ}$.

reach up to $0.5 \mathrm{D}$. The ice accretion profiles with thicknesses of $0.5 \mathrm{D}$ and $1.0 \mathrm{D}$ were both tested in the current experiment, for clarifying the critical ice-accreted cable response. In order to replicate the arbitrary aspect of the ice profile, expandable foam was applied on the cable model. The ice accretion simulated by foam showed good geometrical agreement with the models obtained from the climatic wind tunnels reported in the literature [23], especially for the troughs and crests of the ice accretion. However, the foam also developed small gaps and indentations; the entire ice profile was corrected by applying aluminium foil, and thus, the cable model and the foam ice accretion could better resemble the ice surface smoothness, as it can be seen in Figures 3(a) and 3(b).
Three cable models were tested for vertical and yaw inclinations between $60^{\circ}$ and $15^{\circ}$ as follows (Table 1): Cable Model 1 (CM1) was the cable perpendicular to the flow $\left(0^{\circ}\right)$ and had an aspect ratio of 46, a natural frequency of $0.395 \mathrm{~Hz}$, and a Scruton number of 2.1. This model was also used for $15^{\circ}$ yaw angle tests; Cable Model 2 (CM2) was used for vertical angles of $30^{\circ}$ and $60^{\circ}$ and for yaw angles of $0^{\circ}$ and $15^{\circ}$; this had an aspect ratio of 53.5, a natural frequency of $0.33 \mathrm{~Hz}$, and a Sc $=5.1$. For Cable Model 3 (CM3), the aspect ratio was 92, and the natural frequency was $0.29 \mathrm{~Hz}$ while the Sc number was 10.5 . This cable model was used for tests with $0^{\circ}, 30^{\circ}$, and $60^{\circ}$ vertical angles and $0^{\circ}$ and $15^{\circ}$ yaw angles. The yaw and vertical inclination angles were varied by changing the location of the model, from the middle opening to the last or 


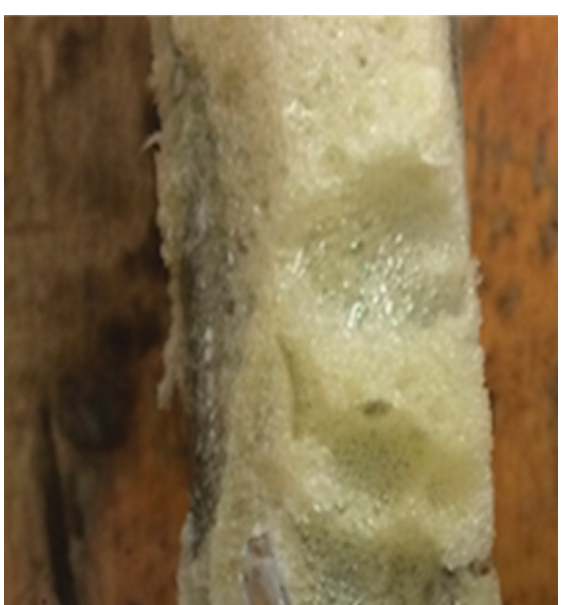

(a)

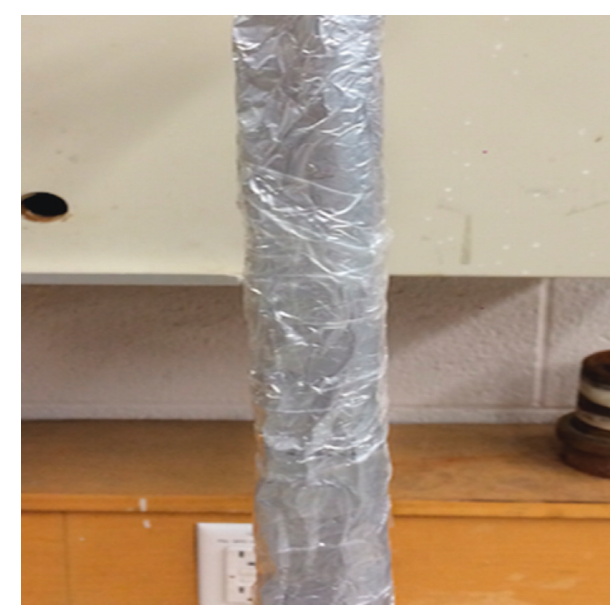

(b)

Figure 3: Bridge cable model with 1.0D ice accretion: (a) initial foam model; (b) foam and aluminium foil model.

TABLE 1: Characteristics of the tested cable models.

\begin{tabular}{lcccccccc}
\hline $\begin{array}{l}\text { Cable } \\
\text { model }\end{array}$ & $\begin{array}{c}\text { Yaw angle, } \\
\alpha\left({ }^{\circ}\right)\end{array}$ & $\begin{array}{c}\text { Vertical angle, } \\
\beta\left({ }^{\circ}\right)\end{array}$ & $\begin{array}{c}\text { Relative angle, } \\
\theta\left(^{\circ}\right)\end{array}$ & $\begin{array}{c}\text { Ice thickness } \\
(\mathrm{D})\end{array}$ & $\begin{array}{c}\text { Damping } \\
\text { ratio }(\%)\end{array}$ & $\begin{array}{c}\text { Frequency } \\
(\mathrm{Hz})\end{array}$ & $\begin{array}{c}\text { Scruton } \\
\text { number }\end{array}$ & $\begin{array}{c}\text { Aspect } \\
\text { ratio }\end{array}$ \\
\hline CM1 & 0 & 0 & 0 & $0.5 \mathrm{D}$ and 1.0D & 0.76 & 0.395 & 2.1 & 46 \\
CM1 & 0 & 15 & 15 & $0.5 \mathrm{D}$ and 1.0D & 0.76 & 0.395 & 2.1 \\
CM2 & 30 & 15 & 33 & $0.5 \mathrm{D}$ & 2.4 & 0.330 & 5.1 \\
CM2 & 30 & 0 & 30 & $0.5 \mathrm{D}$ and 1.0D & 2.4 & 0.330 & 5.1 & 53.5 \\
CM3 & 60 & 0 & 60 & $0.5 \mathrm{D}$ & 3.8 & 0.290 & 10.5 \\
CM3 & 60 & 15 & 61 & $0.5 \mathrm{D}$ & 3.8 & 0.290 & 10.5 & 92 \\
\hline
\end{tabular}

first opening, as represented in Figure 3. Table 1 summarizes the experiments performed for different yaw and vertical inclination angles. The ice accretion profile of $0.5 \mathrm{D}$ was tested for all three cable models, at yaw inclination angles $(\alpha)$ of $0^{\circ}$, $30^{\circ}$, and $60^{\circ}$ and vertical inclination angles $(\beta)$ of $0^{\circ}$ and $15^{\circ}$. Since $1.0 \mathrm{D}$ is considered as an extreme case of the ice accretion thickness, more tests were performed for the $0.5 \mathrm{D}$ ice accretion profile, which is more often encountered.

\section{Vertical and Torsional Wind-Induced Vibrations of Ice-Accreted Cables}

3.1. Effect of Ice Accretion Thickness. The torsional and vertical vibrations for the ice accreted cables were recorded for different wind speeds, from $1.5 \mathrm{~m} / \mathrm{s}$ to $15 \mathrm{~m} / \mathrm{s}$ at intervals of $1.5 \mathrm{~m} / \mathrm{s}$. Figure 4 shows the response time histories for the vertical and rotational vibrations, for the CM1 cable model at $0^{\circ}$ relative angle, with an ice accretion thickness of $0.5 \mathrm{D}$. The maximum vertical and torsional responses were measured as $23.92 \mathrm{~mm}$ and $2.63^{\circ}$, respectively. For the model $\mathrm{CM} 1$ at $0^{\circ}$ relative angle, with $1.0 \mathrm{D}$ ice thickness, Figure 5 reports the vertical and torsional vibrations at $15 \mathrm{~m} / \mathrm{s}$, for which the maximum vertical displacement was $21.95 \mathrm{~mm}$, while the maximum torsional displacement was $5.8^{\circ}$. It is interesting to note that despite the slight decrease in the maximum vertical displacements recorded for the CM1 at $0^{\circ}$, with $1.0 \mathrm{D}$ ice thickness, the maximum torsional response increased by a factor of 2.1, when compared with the CM1 model with $0.5 \mathrm{D}$ ice thickness.
Figure 6 presents the time histories of vertical and torsional response of the cable for model CM2, inclined at relative angle $\theta=30^{\circ}$, for the wind speed of $15 \mathrm{~m} / \mathrm{s}$. In this case, the maximum vertical displacements due to windinduced vibration were recorded as $21.94 \mathrm{~mm}$ at $14.8 \mathrm{~s}$; the maximum vibration amplitude for torsional displacement was $3.13^{\circ}$ at $41 \mathrm{~s}$. The torsional vibration was increasing steadily, but no strong fluctuations were noticed for this case. For higher ice accretion thickness, of $1.0 \mathrm{D}$, the cable model CM2 registered vertical displacement with the maximum value of $27.3 \mathrm{~mm}$, while the mean value for this case was $20.66 \mathrm{~mm}$ (Figure 7(a)). The maximum amplitude of the torsional vibration was $7.3^{\circ}$, as it can be noticed in Figure $7(\mathrm{~b})$, and the average value for this case was $3.3^{\circ}$.

For clarifying the effect of the ice accretion effect on the mean vertical displacement of the tested cables for different wind speeds, the response of the same inclination models, but with $0.5 \mathrm{D}$ and $1.0 \mathrm{D}$ ice accretion thickness, was compared in Figures 8(a)-8(c). As expected, the vertical displacements of all models increased with the increase of wind speed; for lower wind speeds of up to $3.0 \mathrm{~m} / \mathrm{s}$ for CM1 at $\theta=0^{\circ}$ and $\mathrm{CM} 2$ at $\theta=30^{\circ}$ and up to $4.5 \mathrm{~m} / \mathrm{s}$ for CM1 at $\theta=15^{\circ}$, the vertical response for the $0.5 \mathrm{D}$ cable models was consistent with the response of the $1.0 \mathrm{D}$ cable models; however, a sudden decrease in amplitude was noticed for the models with $0.5 \mathrm{D}$ ice accretion at $4.5 \mathrm{~m} / \mathrm{s}$ for $\mathrm{CM} 1$ at $\theta=0^{\circ}$ and at $6 \mathrm{~m} / \mathrm{s}$ for at CM1 at $\theta=15^{\circ}$ and CM2 at $\theta=30^{\circ}$, respectively. The cable models with $1.0 \mathrm{D}$ encounter a small decay in amplitudes at low wind speeds of $4.5 \mathrm{~m} / \mathrm{s}$ for CM2 at 


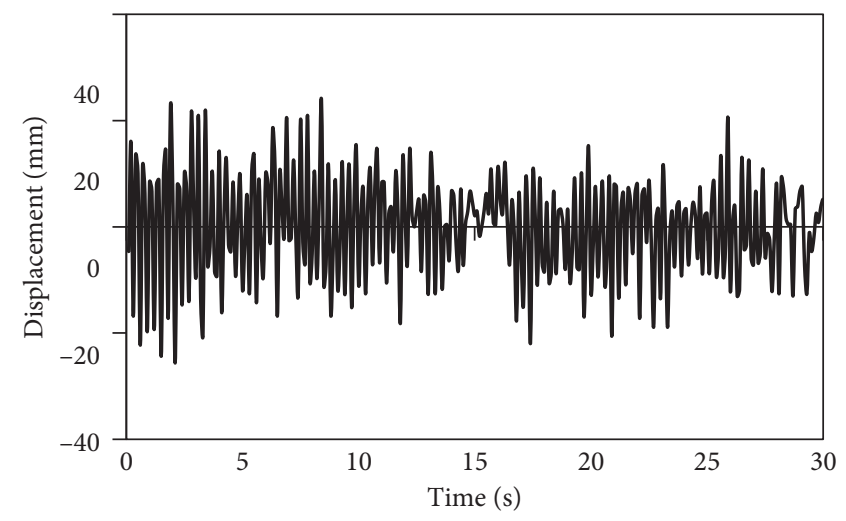

(a)

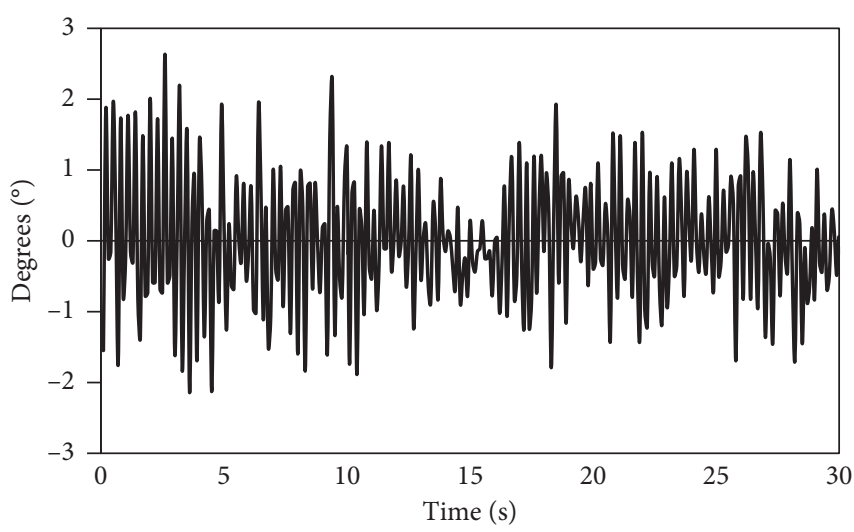

(b)

Figure 4: Time history responses for $\mathrm{CM} 1, \theta=0^{\circ}, 0.5(\mathrm{D})$, at $15 \mathrm{~m} / \mathrm{s}$ : (a) vertical vibration; (b) torsional vibration.

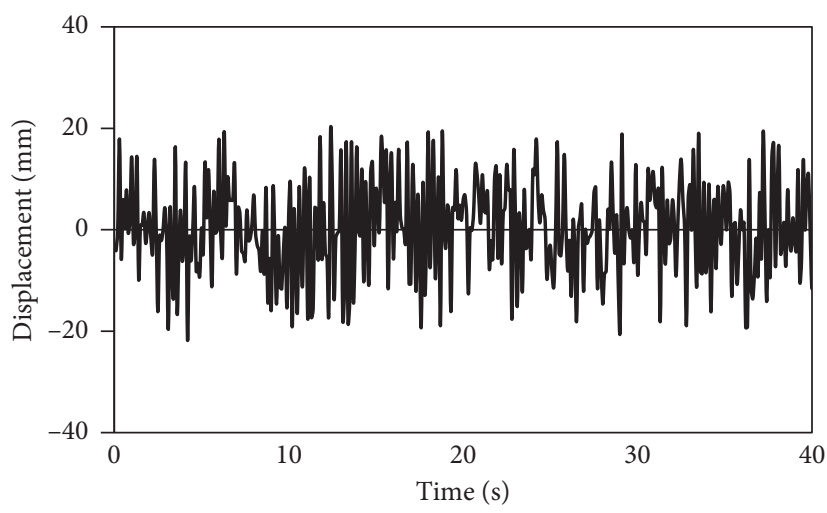

(a)

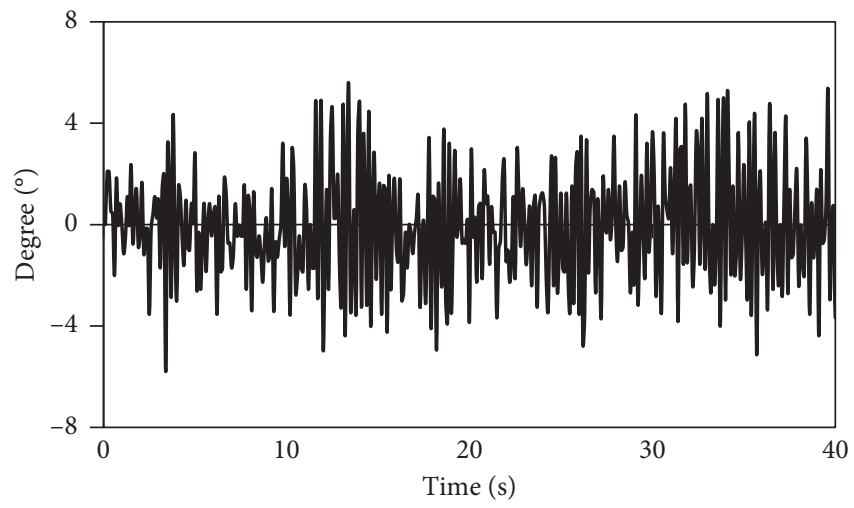

(b)

FIgURE 5: Time history responses for $\mathrm{CM} 1, \theta=0^{\circ}, 1.0(\mathrm{D})$, at $15 \mathrm{~m} / \mathrm{s}$ : (a) vertical vibration; (b) torsional vibration.

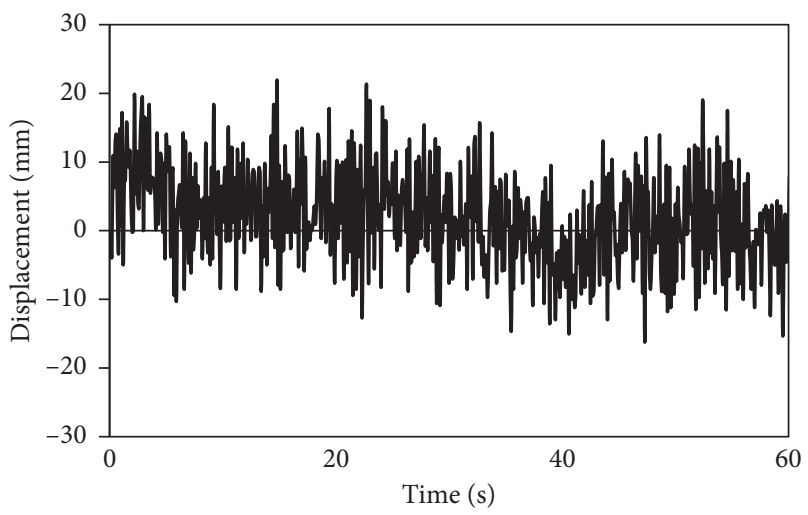

(a)

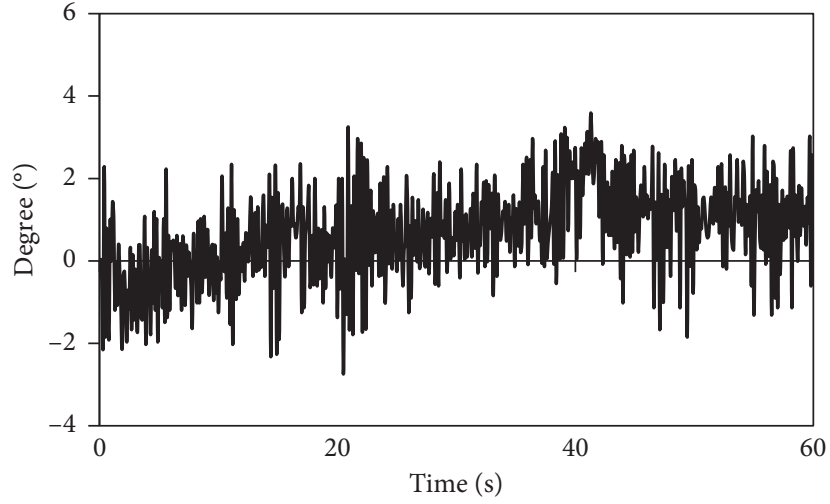

(b)

Figure 6: Time history responses for $\mathrm{CM} 2, \theta=30^{\circ}, 0.5(\mathrm{D})$, at $15 \mathrm{~m} / \mathrm{s}$ : (a) vertical vibration; (b) torsional vibration.

$\theta=30^{\circ}$ and at $7.5 \mathrm{~m} / \mathrm{s}$ for $\mathrm{CM} 1$ at $\theta=15^{\circ}$; however, for the cable model CM1 at $\theta=0^{\circ}$, a sudden increase of amplitudes was noticed for $7.5 \mathrm{~m} / \mathrm{s}$. The vertical vibration response for the cables with 1.0D ice thickness was higher than that of the cable models with $0.5 \mathrm{D}$ ice thickness, especially for wind speeds higher than $9.0 \mathrm{~m} / \mathrm{s}$.
The mean torsional response for the cable model CM2 at $\theta=30^{\circ}$ with $0.5 \mathrm{D}$ ice accretion thickness was more consistent with the mean torsional response of the same inclination cable model, CM2 at $\theta=30^{\circ}$, but with $1.0 \mathrm{D}$ ice accretion, as it can be noticed in Figure 9(C); however, discrepancies were noticed for the other investigated cable models. For CM1 at 


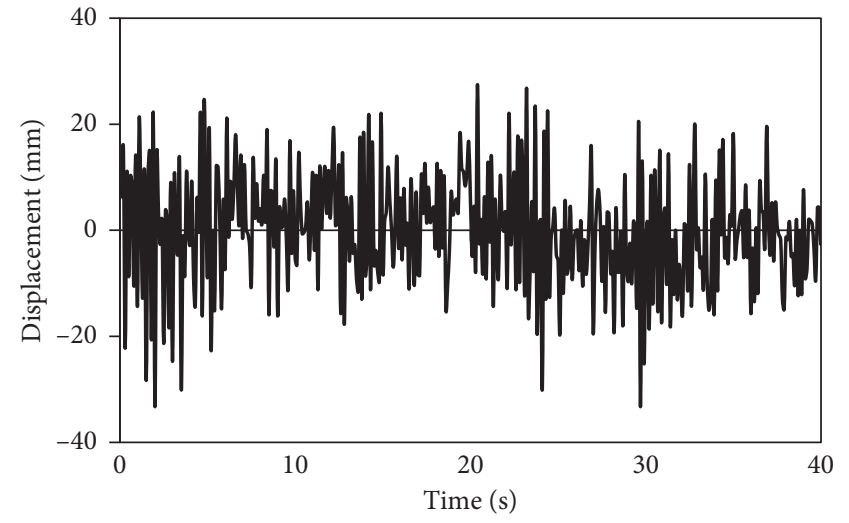

(a)

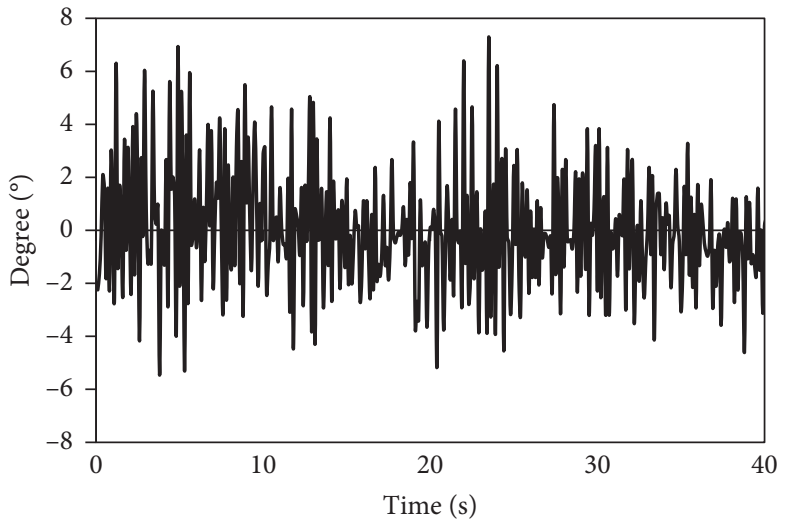

(b)

Figure 7: Time history responses for $\mathrm{CM} 2, \theta=30^{\circ}, 1.0(\mathrm{D})$, at $15 \mathrm{~m} / \mathrm{s}$ : (a) vertical vibration; (b) torsional vibration.
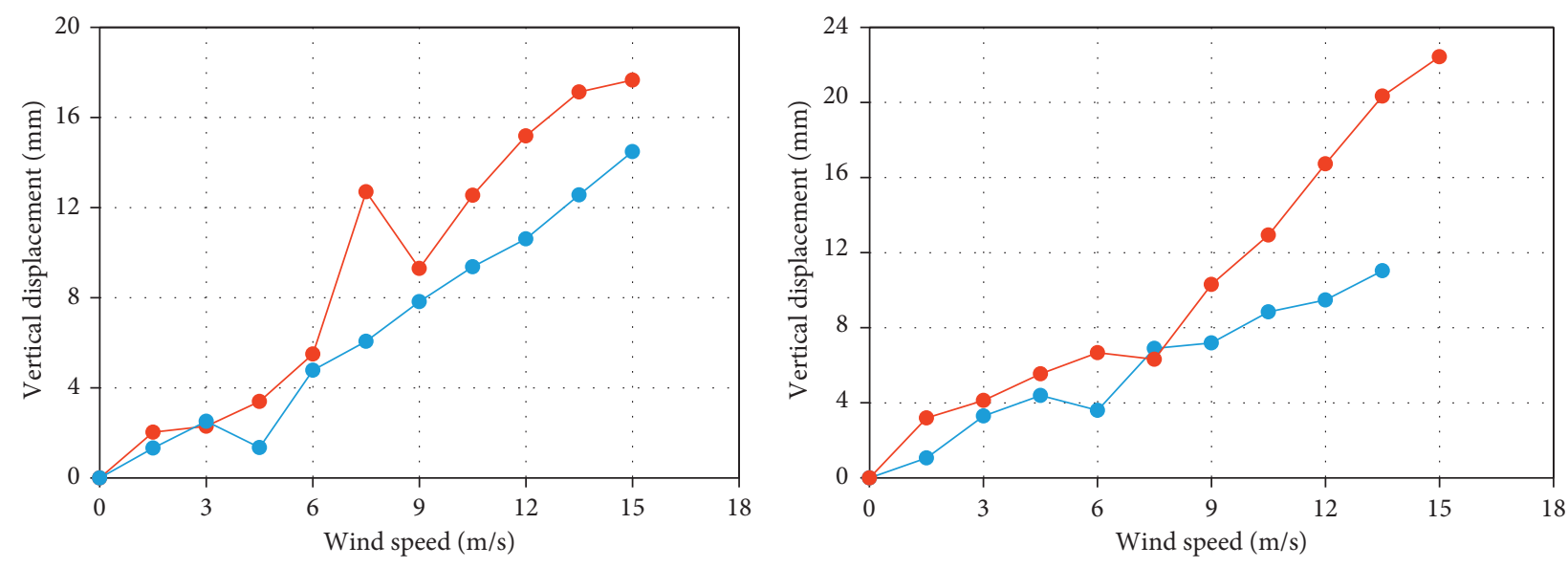

- $\operatorname{CM1}(0.5 D), \theta=0^{\circ}$

- $\operatorname{CM1}(0.5 D), \theta=15^{\circ}$

- $\operatorname{CM1} 1(1.0 D), \theta=0^{\circ}$

- $\mathrm{CM} 1$ (1.0D), $\theta=15^{\circ}$

(a)

(b)

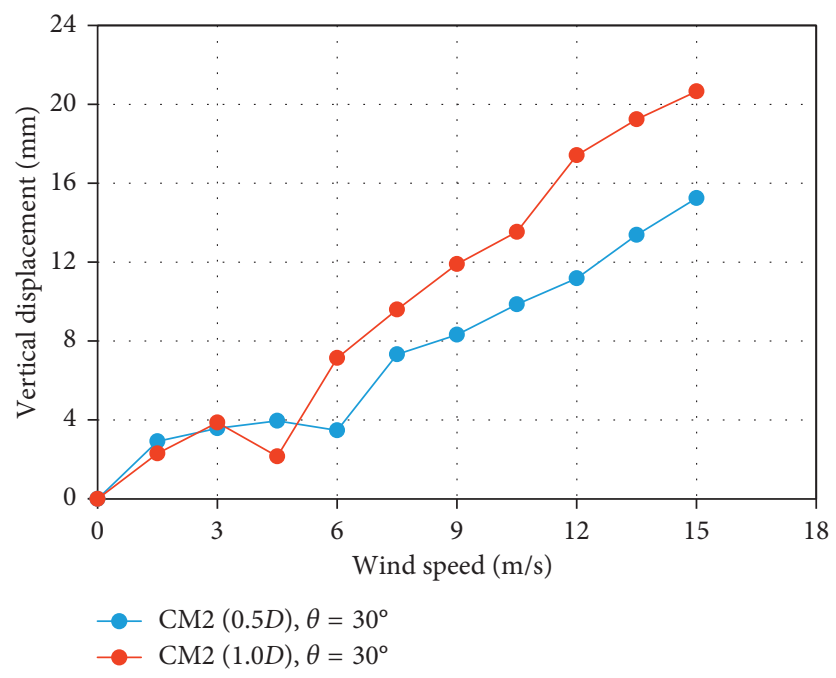

(c)

Figure 8: Variation of mean vertical response with wind speed for cable models with $0.5 \mathrm{D}$ and $1.0 \mathrm{D}$ ice thickness: (a) CM1 at $\theta=0^{\circ}$; (b) CM1 at $\theta=15^{\circ}$; (c) CM2 at $\theta=30^{\circ}$. 


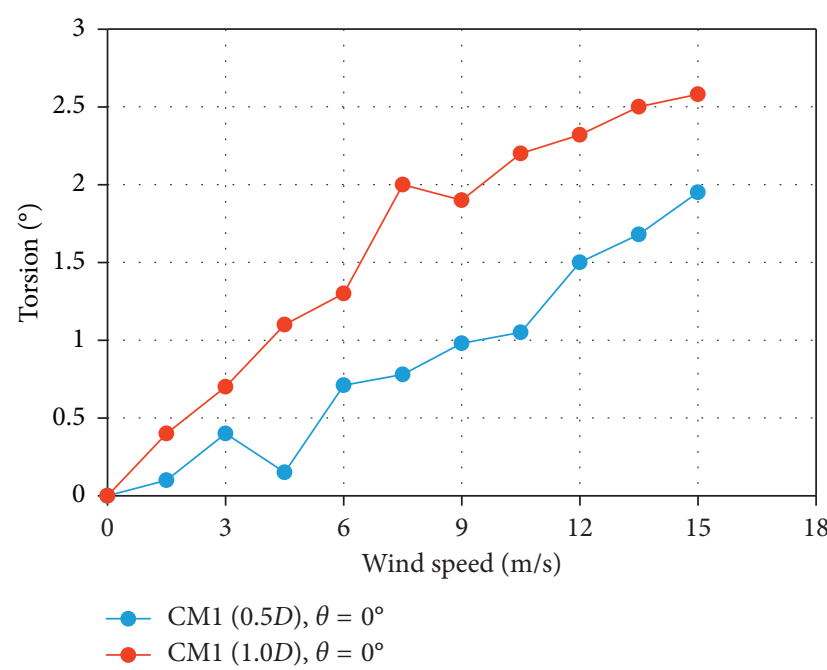

(a)

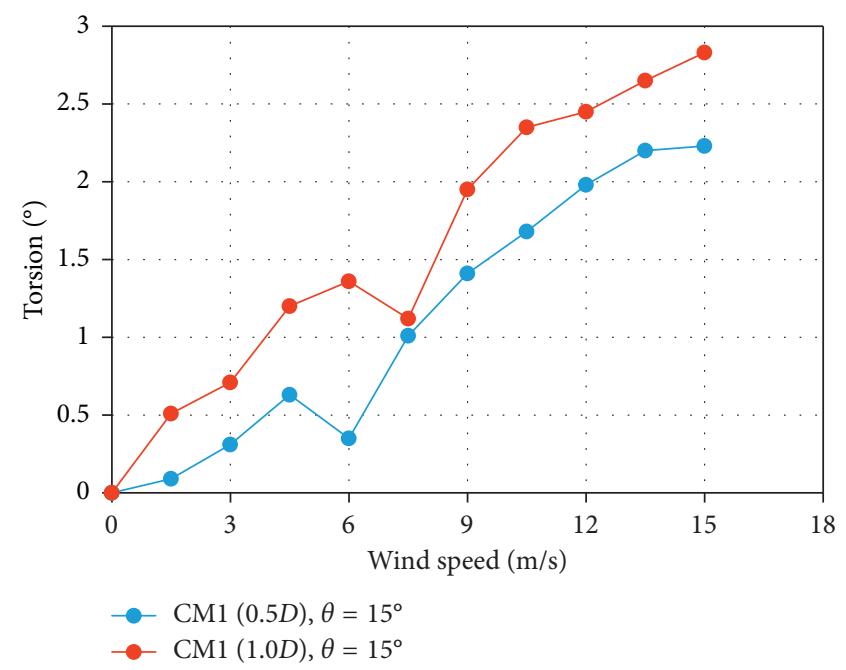

(b)

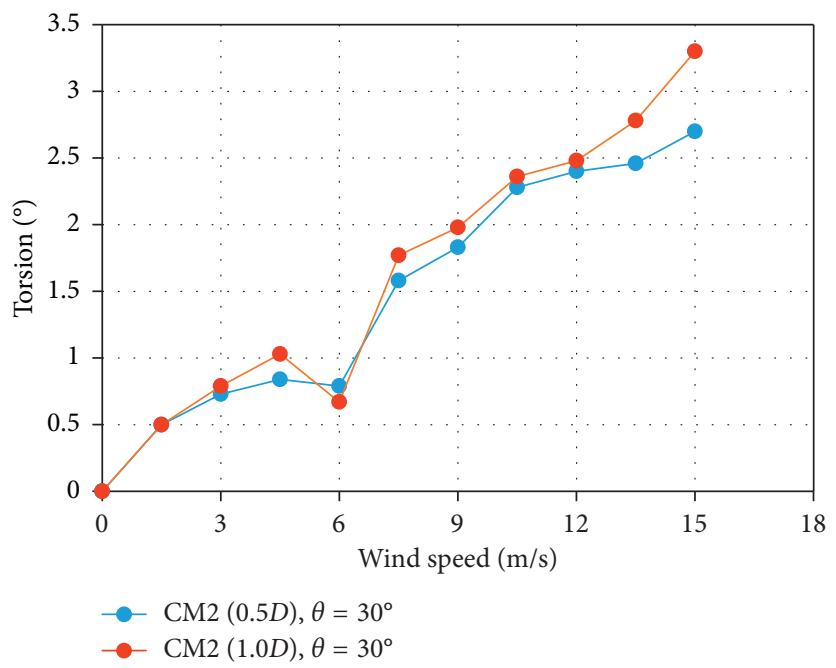

(c)

Figure 9: Variation of mean torsional response with wind speed for cable models with $0.5 \mathrm{D}$ and $1.0 \mathrm{D}$ ice thickness: (a) CM1 at $\theta=0^{\circ}$; (b) $\mathrm{CM} 1$ at $\theta=15^{\circ}$; (c) CM2 at $\theta=30^{\circ}$.

$\theta=0^{\circ}$ and $\mathrm{CM} 1$ at $\theta=15^{\circ}$, the mean torsional response was higher for $1.0 \mathrm{D}$ ice accretion thickness, when compared with the $0.5 \mathrm{D}$ ice accretion models, for all the tested wind speeds (Figures 8(a) and 8(b)). Sudden decays in amplitude were still noticed for models with $0.5 \mathrm{D}$ ice thickness at lower wind speeds of $4.5 \mathrm{~m} / \mathrm{s}$ and $6 \mathrm{~m} / \mathrm{s}$ for the CM1 and CM2 models, respectively, while for $1.0 \mathrm{D}$ ice thickness models, the torsional response decay occurred at $7.5 \mathrm{~m} / \mathrm{s}$ and $4.5 \mathrm{~m} / \mathrm{s}$ for models CM1 and CM2, respectively.

3.2. Effect of Relative Angle. The average amplitudes for vertical and torsional vibrations were investigated for different relative angles of attack, $\theta$, and it was noticed that the highest responses corresponded to the highest relative angles. For the cases with $0.5 \mathrm{D}$ ice accretion, the cable models CM3 at $\theta=61^{\circ}$ and $\theta=60^{\circ}$ showed the highest vertical and torsional responses (Figures 10(a) and 11(a)), which is similar to the critical cases reported by Cheng et al. [2] for vertically and horizontally inclined stay cables, without ice accretion. Also for relative angles of $60^{\circ}$ and $61^{\circ}$, the sudden decay of amplitude at lower wind speeds was not noticed. For the CM2 cable model, both vertical and torsional responses were smaller for wind speeds up to $3.0 \mathrm{~m} / \mathrm{s}$; however, from $4.5 \mathrm{~m} / \mathrm{s}$ and up to $10.5 \mathrm{~m} / \mathrm{s}$, the responses for the model inclined at relative angle $33^{\circ}$ were higher than the one registered for the model inclined at relative angle $30^{\circ}$ (Figures 10(b) and 11(b)).

In general, for CM3 and CM2 models, the torsional and vertical mean responses were higher for higher relative angles; however, by comparing the magnitude of the recorded vibrations, it can be concluded that the vibrations were consistent with each other, for different wind speeds. For the CM1 model, the mean vertical response was higher for $\theta=0^{\circ}$ at higher wind speeds between $9.0 \mathrm{~m} / \mathrm{s}$ and $13.5 \mathrm{~m} / \mathrm{s}$ and at $6 \mathrm{~m} / \mathrm{s}$ (Figure $10(\mathrm{c})$ ); the mean torsional response however was much higher for the CM1 model at $\theta=15^{\circ}$ between wind speeds of $7.5 \mathrm{~m} / \mathrm{s}$ and $15 \mathrm{~m} / \mathrm{s}$ and at $6 \mathrm{~m} / \mathrm{s}$ (Figure $11(\mathrm{c})$ ). 


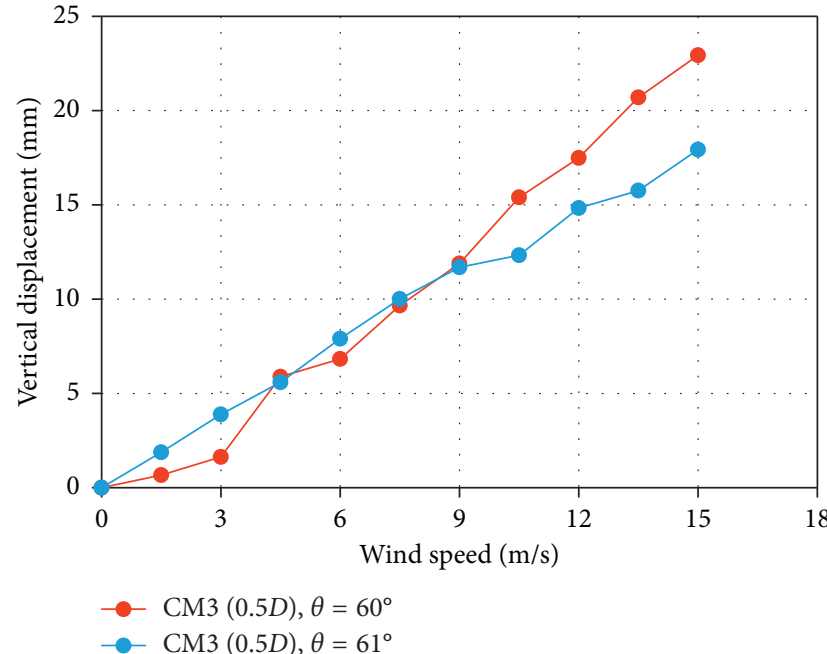

(a)

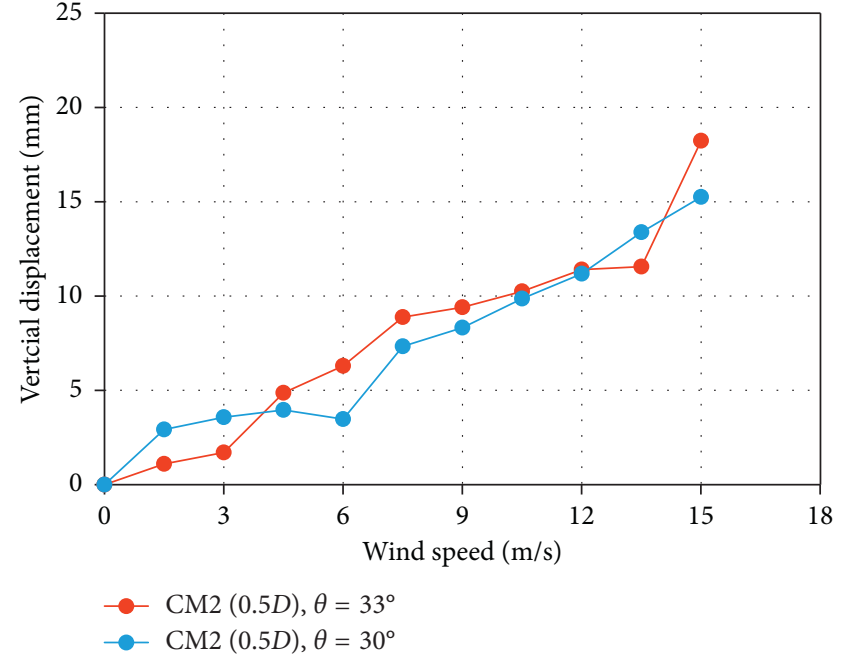

(b)

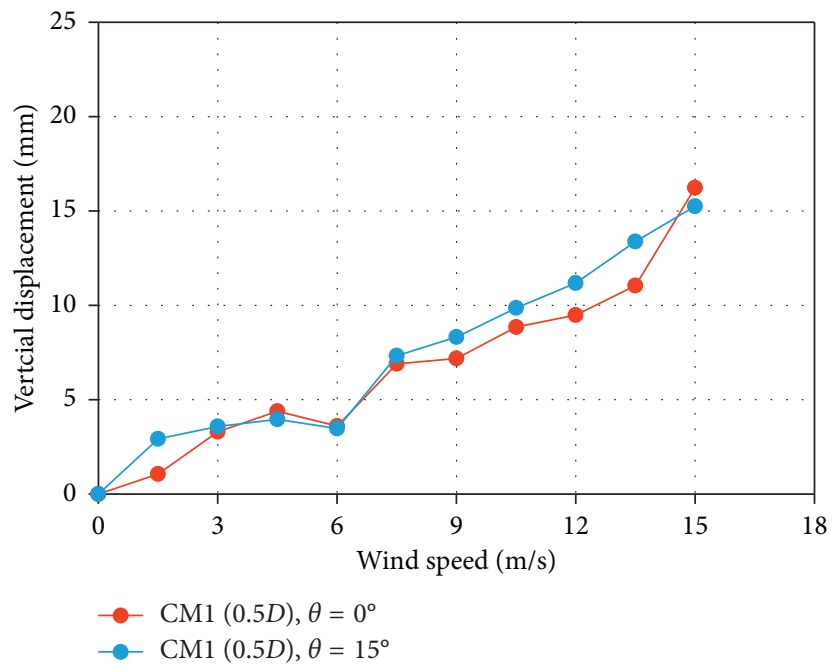

(c)

Figure 10: Variation of mean vertical response with wind speed for cable models with $0.5 \mathrm{D}$ ice thickness: (a) $\mathrm{CM} 3$ at $\theta=60^{\circ}$ and $\theta=61^{\circ}$; (b) $\mathrm{CM} 2$ at $\theta=30^{\circ}$ and $\theta=33^{\circ}$; (c) $\mathrm{CM} 1$ at $\theta=0^{\circ}$ and $\theta=15^{\circ}$.

3.3. Wind-Induced Response Frequency Analysis. In order to observe the variation of the response frequency under different wind speeds, Fast Fourier transform (FFT) was applied for the measured vertical vibrations and the dominant frequency for each response time history was identified. The spectral distribution obtained through the FFT analysis showed very small frequencies without a dominant peak for wind speeds lower than $3.0 \mathrm{~m} / \mathrm{s}$ for $\mathrm{CM} 1$ at $0^{\circ}$, with $0.5 \mathrm{D}$ ice accretion, and for $\mathrm{CM} 2$ at $30^{\circ}$, with $1.0 \mathrm{D}$ ice accretion; frequencies difficult to identify were noticed for wind speeds lower than $4.5 \mathrm{~m} / \mathrm{s}$ for models $\mathrm{CM} 1$ at $0^{\circ}$ with $1.0 \mathrm{D}$ ice accretion and CM2 at $30^{\circ}$ with $0.5 \mathrm{D}$ ice accretion, as represented in Figures 12(a) and 12(b).

The frequencies of the wind-induced response were higher for the models CM1 at $0^{\circ}$ and CM2 at $30^{\circ}$ models with higher ice accretion (1.0D), having a similar trend of slightly higher frequencies at $10.5 \mathrm{~m} / \mathrm{s}$ and at $15 \mathrm{~m} / \mathrm{s}$. For $10.5 \mathrm{~m} / \mathrm{s}$ wind speed, other peaks, of smaller intensity, were identified in the FFT spectra, around frequencies of $0.025 \mathrm{~Hz}$ and $0.21 \mathrm{~Hz}$ for the model CM1 at $0^{\circ}$ and $0.025 \mathrm{~Hz}$ for the model $\mathrm{CM} 2$ at $30^{\circ}$, both with $1.0 \mathrm{D}$ ice accretion (Figures 13 (a) and $13(\mathrm{~b}))$. For the $0.5 \mathrm{D}$ ice accretion, the two models, CM1 at $0^{\circ}$ and $\mathrm{CM} 2$ at $30^{\circ}$, showed trends similar to each other, for the vertical response frequencies obtained at the wind speeds between $4.5 \mathrm{~m} / \mathrm{s}$ and $15 \mathrm{~m} / \mathrm{s}$ were (Figures 12(b)), with a slight increase at $6.0 \mathrm{~m} / \mathrm{s}$ and a sudden decrease at $10.5 \mathrm{~m} / \mathrm{s}$, followed by an ascending frequency at $15 \mathrm{~m} / \mathrm{s}$, of up to $0.34 \mathrm{~Hz}$ for the model CM1 at $0^{\circ}$ and up to $0.4 \mathrm{~Hz}$ for the model CM2 at $30^{\circ}$, both with $0.5 \mathrm{D}$ ice accretion. A second peak at $0.18 \mathrm{~Hz}$ was noticed only for the model CM2 at $30^{\circ}$, at $10.5 \mathrm{~m} / \mathrm{s}$ (Figure 14(b)), while a single dominant frequency at $0.3303 \mathrm{~Hz}$ was signaled for the CM1 at $0^{\circ}$ model.

Any changes of the frequency can indicate the change of the dynamic response of the cable model, under the effect of the increasing wind speed. As shown in Figures 8 and 10, a sudden decrease in the frequency response is observed at 


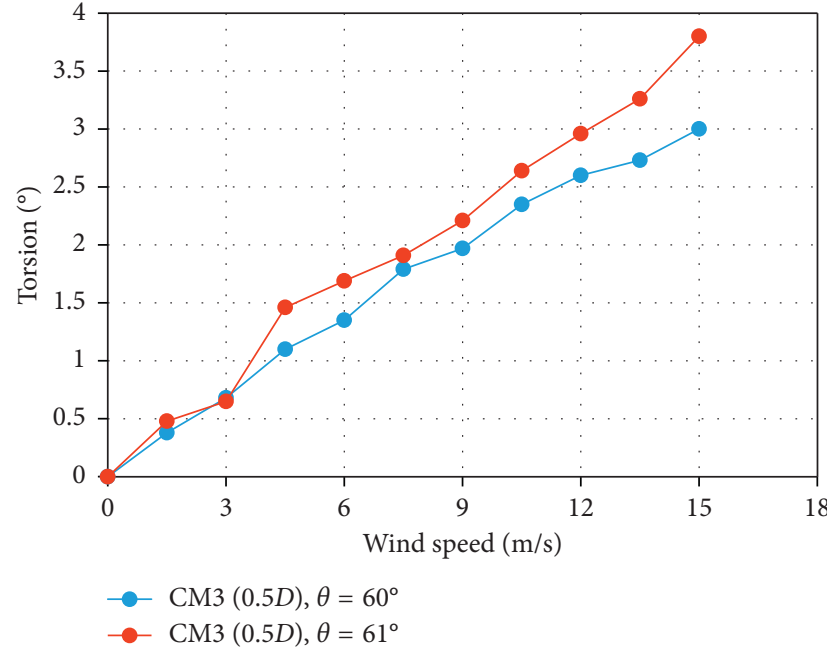

(a)

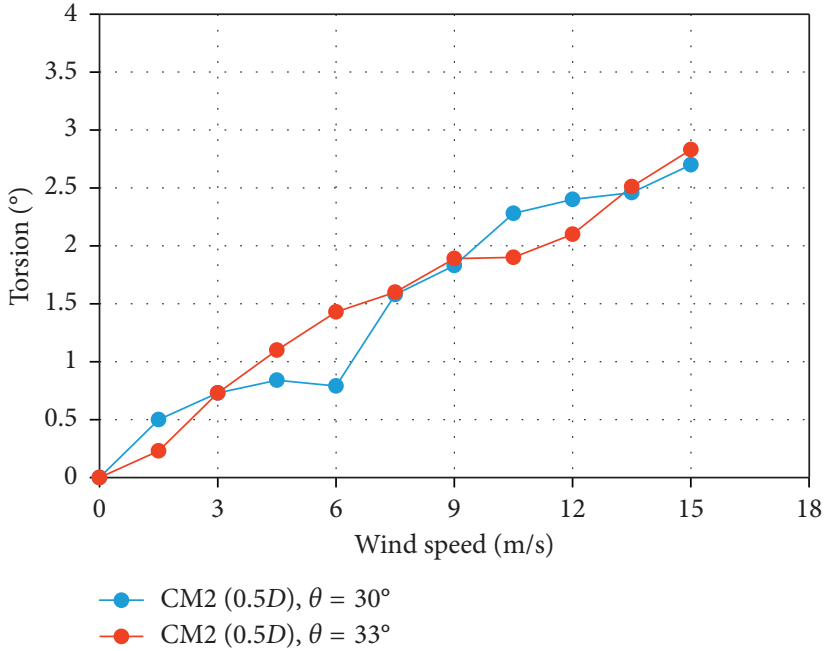

(b)

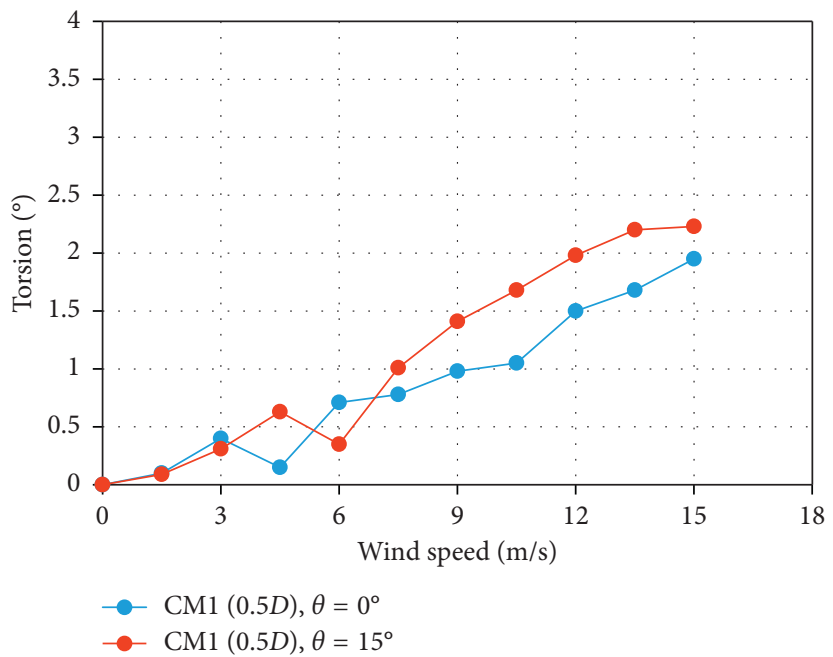

(c)

Figure 11: Variation of mean torsional response with wind speed for cable models with $0.5 \mathrm{D}$ ice thickness: (a) $\mathrm{CM} 3$ at $\theta=60^{\circ}$ and $\theta=61^{\circ}$; (b) CM2 at $\theta=30^{\circ}$ and $\theta=33^{\circ}$; (c) CM1 at $\theta=0^{\circ}$ and $\theta=15^{\circ}$.

$4.5 \mathrm{~m} / \mathrm{s}$ for the models CM1 at $\theta=0^{\circ}, 0.5 \mathrm{D}, \mathrm{CM} 2$ at $\theta=30^{\circ}$, $1.0 \mathrm{D}$, which corresponds to a low frequency point in the vertical vibration FFT shown in Figures 12(a) and 12(b), for the same wind speed. Similarly, for other models, such as $\mathrm{CM} 1$ at $\theta=15^{\circ}, 0.5 \mathrm{D}$ and $1.0 \mathrm{D}$, and $\mathrm{CM} 2$ at $\theta=30^{\circ}, 0.5 \mathrm{D}$, the sudden decrease of the vertical response occurred at $6.0 \mathrm{~m} / \mathrm{s}$ (Figures 8 and 10), which correspond to a low frequency point as well (Figure 12).

In order to compare the frequencies for the windinduced response recorded at different wind speeds, for cable models with $0.5 \mathrm{D}$ and $1.0 \mathrm{D}$ ice accretion profiles, the variation of the Strouhal number for the aforementioned cases was investigated. The Strouhal number was determined as $S t=f D_{\text {eq }} / \mathrm{U}$, where $f, D_{\text {eq }}$, and $\mathrm{U}$ are the frequency of the vertical response, and the equivalent diameter of each cable model was exposed to the wind direction and the mean wind speed, respectively. It should be noted that the thickness of the ice accretion on the cable and the relative cable-wind direction angle were considered in estimating the equivalent cable diameter, $D_{\text {eq }}$, for the Strouhal number calculation, as shown in Equation (1). Also, $D_{\text {eq }}$, in Equation (1), is the equivalent cable diameter considering the ice thickness and relative cable-wind direction angle; $D_{c}$ and $h_{i}$ are the cable diameter and mean thickness of the ice profile, respectively, while $\theta$ is the relative wind-cable direction angle:

$$
D_{\text {eq }}=\left(D_{c}+h_{i}\right) \times \cos (\theta) \text {. }
$$

Figure 15 shows that despite the frequency variations indicated in Figure 10, the normalized frequencies (Strouhal numbers) for all the performed cases decreased with the increase of wind speed, as expected. Also Figure 15 shows that, for different relative wind-cable angles, the normalized frequencies for the cases with the same ice thickness were almost identical. According to Hao [28], the galloping divergent vibration can occur for Strouhal numbers lower than 0.05 , the value corresponding to the horizontal dashed line in Figure 15, showing the incipient conditions from which the galloping divergent vibration 


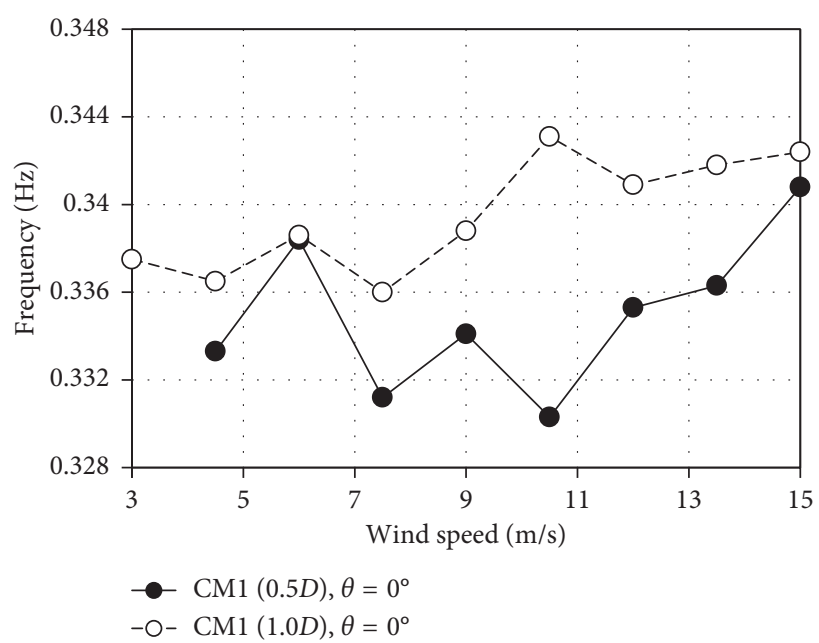

(a)

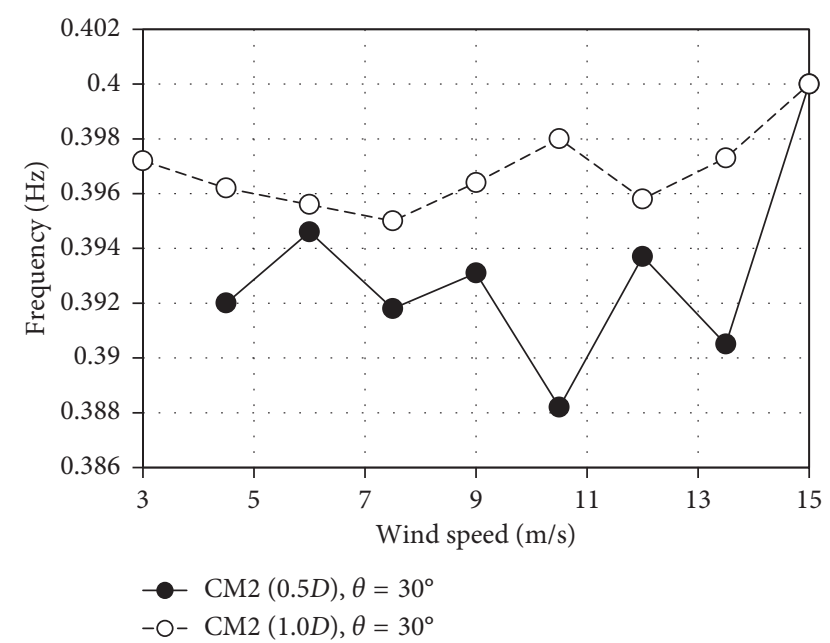

(b)

Figure 12: Vertical vibrations frequencies for models with $0.5 \mathrm{D}$ and $1.0 \mathrm{D}$ ice accretion: (a) $\mathrm{CM} 1\left(\theta=0^{\circ}\right)$; (b) $\mathrm{CM} 2\left(\theta=30^{\circ}\right)$.

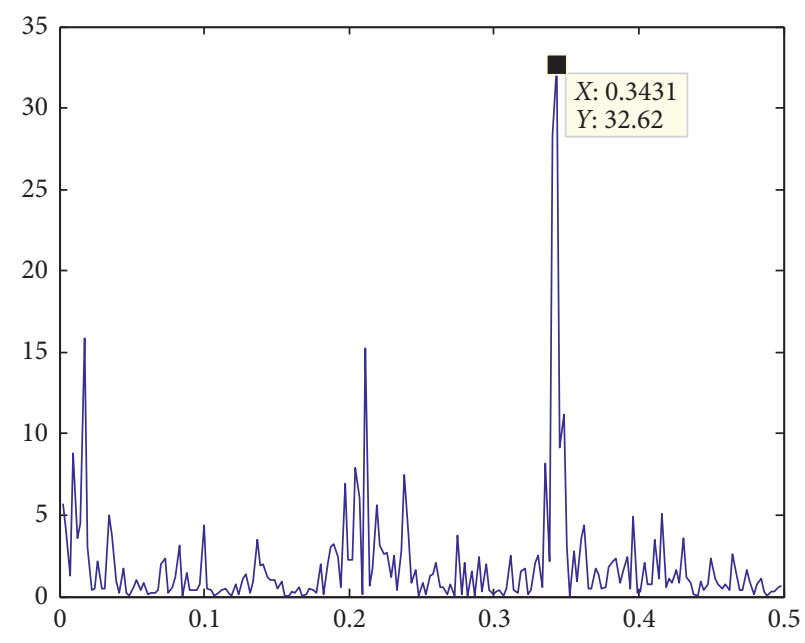

(a)

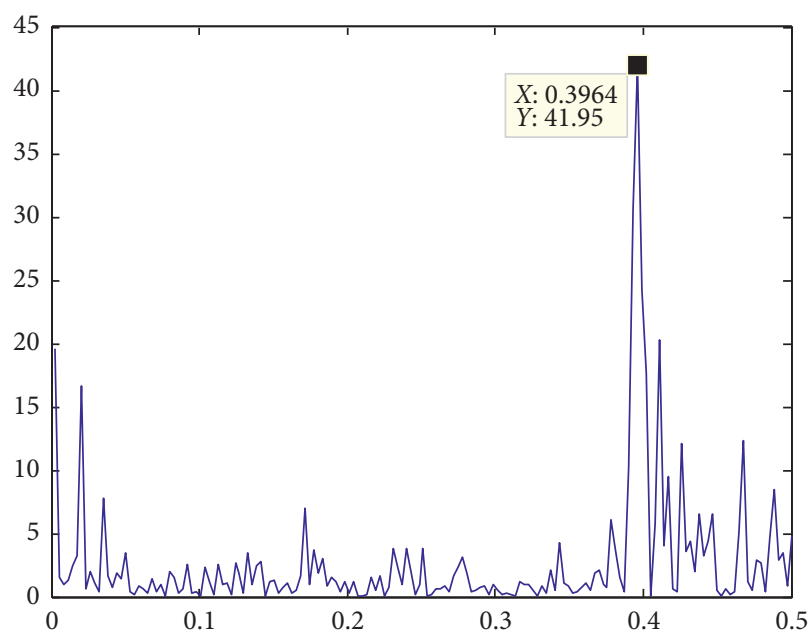

(b)

Figure 13: FFT distribution of frequencies for models with an ice thickness of $1.0 \mathrm{D}$ at $10.5 \mathrm{~m} / \mathrm{s}$ for (a) $\mathrm{CM} 1\left(\theta=0^{\circ}\right)$ and $(\mathrm{b}) \mathrm{CM} 2\left(\theta=30^{\circ}\right)$.

could occur, for both cable models, with $0.5 \mathrm{D}$ ice accretion and with 1.0D ice accretion, from wind tunnel wind speeds as low as $3.0 \mathrm{~m} / \mathrm{s}$.

The critical wind speed, after which galloping instability can be expected, for all cable models tested can be determined using Equation (2) $[16,29]$. In Equation (2), $U_{\text {crit }}$, $f, D$, and $S_{c}$ are critical wind speed, natural frequency of the fundamental mode of vibration, cable diameter, and the Scruton number, respectively:

$$
U_{\text {crit }}=40 f D \sqrt{S_{c}} \text {. }
$$

Using Equation (2), the critical wind speeds were determined spanned between $4.5 \mathrm{~m} / \mathrm{s}$ and $10.5 \mathrm{~m} / \mathrm{s}$ for the models $\mathrm{CM} 1$ at $\theta=0^{\circ}$ with $0.5 \mathrm{D}$ and $\mathrm{CM} 3$ at $\theta=61^{\circ}$ with $1.0 \mathrm{D}$, respectively. These wind speeds coincide with the sudden changes in the vertical response frequencies presented in Figures 8 and 10, showing that the higher wind-induced response occurred at different wind speeds, depending on the relative angle of attack and the thickness of the ice profile tested.

\section{Conclusions}

Cable-stayed bridges stability rely on all the structural members composing these massive structures, and the stay cables, which are the most flexible elements of the bridge, and have a significant role in the overall bridge design. The wind tunnel experiment performed for cables with ice accretion reported herewith clarifies some aspects related to the wind-induced response for the ice-accreted bridge yawed and inclined stay cables. Different parameters such as the vertical inclination angle $\left(0^{\circ}\right.$ and $\left.15^{\circ}\right)$, yaw angle $\left(0^{\circ}, 15^{\circ}, 30^{\circ}\right.$, and $\left.60^{\circ}\right)$, ice accretion profile thickness $(0.5 \mathrm{D}$ and $1.0 \mathrm{D})$, and wind tunnel wind speed ( 1.5 to $15 \mathrm{~m} / \mathrm{s}$ ) were considered. The increase of ice accretion thickness was shown to increase the wind-induced response, especially for wind speeds higher 


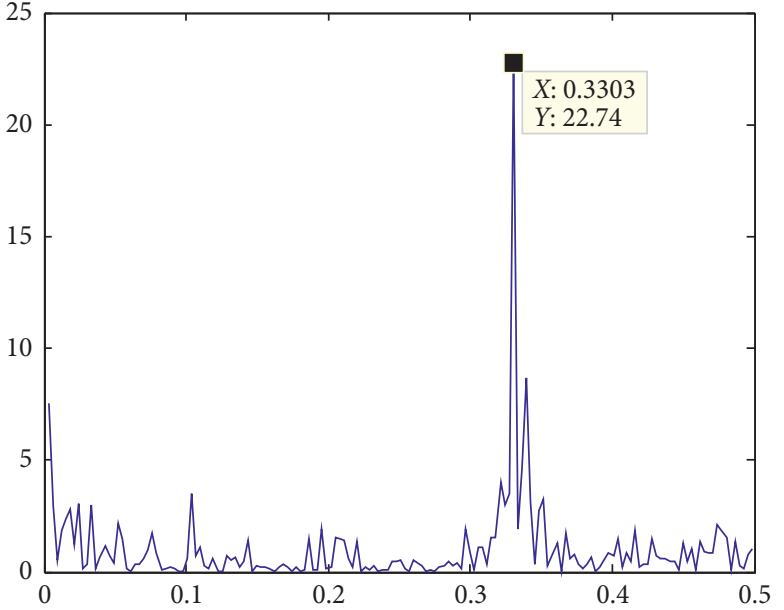

(a)

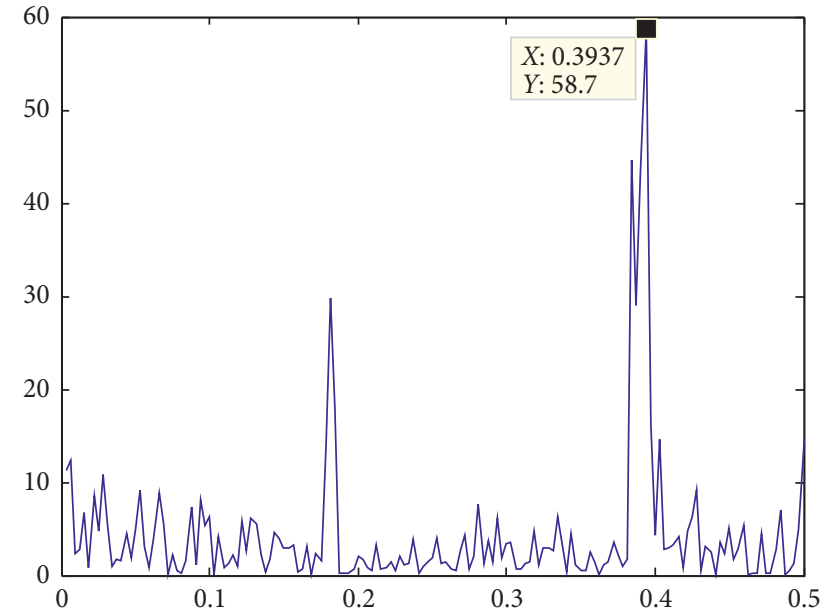

(b)

FIGURE 14: FFT distribution of frequencies for models with an ice thickness of $0.5 \mathrm{D}$ at $10.5 \mathrm{~m} / \mathrm{s}$ for (a) CM1 $\left(\theta=0^{\circ}\right)$ and $(\mathrm{b}) \mathrm{CM} 2\left(\theta=30^{\circ}\right)$.

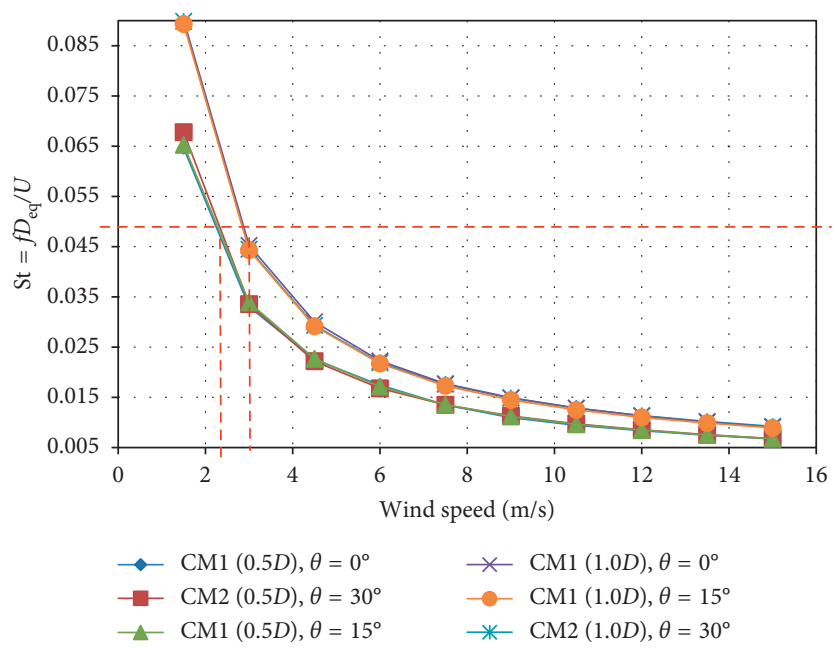

Figure 15: Normalized frequency $\left(\mathrm{St}=f D_{\mathrm{eq}} / U\right)$ for the vertical vibrations.

than $4.5 \mathrm{~m} / \mathrm{s}$. Both vertical and torsional displacements increased with the increase of the relative angles of attack; however, the investigated angles did not determine a significant increase of the wind-induced response for the $0.5 \mathrm{D}$ and 1.0D ice-accreted stay cables. Also, at certain wind speeds, the vibration for the cables with higher inclination angles was smaller than the cases with lower inclinations; however, for wind speeds beyond $7.5 \mathrm{~m} / \mathrm{s}$, the response of the cables with higher inclination angles surpassed the case with lower inclination angles. A sudden decrease in the vertical vibration occurred for models CM1 at $\theta=0^{\circ}, 0.5 \mathrm{D}, \mathrm{CM} 2$ at $\theta=30^{\circ}, 1.0 \mathrm{D}$, and $\mathrm{CM} 2$ at $\theta=33^{\circ}, 1.0 \mathrm{D}$, for wind tunnel wind speeds of $4.5 \mathrm{~m} / \mathrm{s}$, for which the frequency analysis showed lower frequency points. A similar decrease in response was noticed at wind speeds of $6.0 \mathrm{~m} / \mathrm{s}$ and above, for models $\mathrm{CM} 1$ at $\theta=15^{\circ}, 0.5 \mathrm{D}$ and $1.0 \mathrm{D}$, and CM2 at $\theta=30^{\circ}, 0.5 \mathrm{D}$. The frequency analysis showed multiple vibration values for the vertical wind-induced response between wind speeds $4.5 \mathrm{~m} / \mathrm{s}$ and $9.0 \mathrm{~m} / \mathrm{s}$ for models with $0.5 \mathrm{D}$ ice accretion and between wind speeds of $7.5 \mathrm{~m} / \mathrm{s}$ and $15 \mathrm{~m} / \mathrm{s}$ for models with $1.0 \mathrm{D}$ ice accretion, which can be an indication of an aerodynamic instability.

\section{Data Availability}

The data supporting the current research project can be found at CVG Department, University of Ottawa, and can be made available if necessary by the authors.

\section{Conflicts of Interest}

The authors declare that they have no conflicts of interest.

\section{Acknowledgments}

This work was supported by the Natural Sciences and Engineering Research Council of Canada (NSERC), Discovery Grant 06776, 2015. 


\section{References}

[1] M. Matsumoto, H. Shirato, T. Yagi, M. Goto, S. Sakai, and J. Ohya, "Field observation of th full-scale wind-induced cable vibration," Journal of Wind Engineering and Industrial Aerodynamics, vol. 91, no. 1-2, pp. 13-26, 1995.

[2] S. Cheng, G. L. Larose, M. G. Savage, H. Tanaka, and P. A. Irwin, "Experimental study on the wind-induced vibration of a dry inclined cable-part I: phenomena," Journal of Wind Engineering and Industrial Aerodynamics, vol. 96, no. 12, pp. 2231-2253, 2008.

[3] M. Raoof, "Free-bending fatigue life estimation of cables at points of fixity," Journal of Engineering Mechanics, vol. 118, no. 9, pp. 1747-1764, 1992.

[4] J. Druez, S. Louchez, and P. McComber, "Ice shedding from cables," Cold Regions Science and Technology, vol. 23, no. 4, pp. 377-388, 1995.

[5] D. Zuo and N. P. Jones, Stay-cable Vibration Monitoring of the Fred Hartman Bridge (Houston, Texas) and the Veterans Memorial Bridge (Port Arthur, Texas), Center for Transportation Research, Bureau of Engineering Research, University of Texas at Austin, Austin, TX, USA, 2005.

[6] A. Davenport, "Buffeting of a suspension bridge by storm winds," ASCE Journal of Structural Division, vol. 88, no. 3, pp. 233-268, 1962.

[7] D. H. Yeo and N. P. Jones, "Computational study on 3-D aerodynamic characteristics of flow around a yawed, inclined, circular cylinder," NSEL Report Series, Report No. NSEL-027, University of Illinois at Urbana-Champaign, Champaign, IL, USA, 2011.

[8] M. Matsumoto, N. Shiraishi, and H. Shirato, "Rain-wind induced vibration of cables of cable-stayed bridges," Journal of Wind Engineering and Industrial Aerodynamics, vol. 43, no. 1-3, pp. 2011-2022, 1992.

[9] M. Matsumoto, T. Yagi, H. Hatsudab, T. Shimac, M. Tanakad, and H. Naitoa, "Dry galloping characteristics and its mechanism of inclined/yawed cables," Journal of Wind Engineering and Industrial Aerodynamics, vol. 98, no. 6-7, pp. 317-327, 2010.

[10] Q. Liu, F. Zhang, M. Wenyong, and W. Yi, "Experimental study on Reynolds number effect on dry cable galloping of stay cables," in Proceedings of the 13th International Conference on Wind Engineering, Amsterdam, Netherlands, July 2011.

[11] J. H. G. Macdonald and G. L. Larose, "A unified approach to aerodynamic damping and drag/lift instabilities, and its application to dry inclined cable galloping," Journal of Fluids and Structures, vol. 22, no. 2, pp. 229-252, 2006.

[12] M. S. Hoftyzer and E. Dragomirescu, "Numerical investigation of flow behaviour around inclined circular cylinders," in Proceedings of the Fifth International Symposium on Computational Wind Engineering (CWE2010), Chapel Hill, NC, USA, May 2010.

[13] M. Matsumoto, Y. Shigemura, Y. Daito, and T. Kanamura, "High speed vortex shedding vibration of inclined cables," in Proceedings of the Second International Symposium on Cable Dynamics, pp. 27-35, Tokyo, Japan, October 1997.

[14] W. Martin, E. Naudascher, and I. Currie, "Streamwise oscillations of cylinders," Journal of the Engineering Mechanics Division, vol. 107, pp. 589-607, 1981.

[15] H. Tabatabai, Inspection and Maintenance of Bridge Stay Cable Systems, NCHRP Synthesis 353, National Cooperative Research Program, Transportation Research Board, 2005.
[16] S. Kumarasena, N. P. Jones, P. Irwin, and P. Taylor, WindInduced Vibration of Stay Cables, US Department of Transportation, Federal Highway Association, Publication No. FHWA-RD-05-083, Washington, DC, USA, 2007.

[17] N.J. Gimsing and C.T. Georgakis, Cable Supported Bridges: Concept and Design, Wiley, Chichester, England, 2011.

[18] P. McComber and A. Paradis, "A cable galloping model for thin ice accretions," Atmospheric Research, vol. 46, no. 1-2, pp. 13-25, 1998.

[19] C. Demartino, H. H. Koss, C. T. Georgakis, and F. Ricciardelli, "Effects of ice accretion on the aerodynamics of bridge cables," Journal of Wind Engineering and Industrial Aerodynamics, vol. 138, pp. 98-119, 2015.

[20] H. Gjelstrup, C. T. Georgakis, and A. Larsen, "An evaluation of iced bridge hanger vibrations through wind tunnel testing and quasi-steady theory," Wind and Structures An International Journal, vol. 15, no. 5, pp. 385-407, 2012.

[21] L. J. Vincentsen and P. Lundhus, The Øresund and the Great Belt links-Experience and Developments, IABSE SymposiumWeimar, Germany, 2007.

[22] H. H. Koss and G. Matteoni, "Experimental investigation of aerodynamic loads on iced cylinders," in Proceedings of 9th International Symposium on Cable Dynamics, Shanghai, October 2011.

[23] H. H. Koss, H. Gjelstrup, and C. T. Georgakis, "Experimental study of ice accretion on circular cylinders at moderate low temperatures," Journal of Wind Engineering and Industrial Aerodynamics, vol. 104-106, pp. 540-546, 2012.

[24] H. H. Koss and M. S. M. Lund, "Experimental investigation of aerodynamic instability of iced bridge sections," in Proceedings of 6th European and African Conference on Wind Engineering, Robinson College, Cambridge, UK, July 2013.

[25] H. H. Koss, J. F. Henningsen, and I. Olsenn, "Influence of icing on bridge cable aerodynamics," in Proceedings of Fifteenth International Workshop on Atmospheric Icing of Structures, St.John's, Newfoundland and Labrador, Canada, September 2013.

[26] C. Demartino and F. Ricciardelli, "Aerodynamic stability of ice-accreted bridge cables," Journal of Fluids and Structures, vol. 52, pp. 81-100, 2015.

[27] G. S. West and C. J. Apelt, "The effects of tunnel blockage and aspect ratio on the mean flow past a circular cylinder with Reynolds numbers between 104 and 105," Journal of Fluid Mechanics, vol. 114, no. 1, pp. 361-377, 1982.

[28] H. Hao, "The galloping phenomenon and its control of bridges," Master's thesis, Chang'an University, Xi'an, China, 2010, in Chinese.

[29] T. Saito, M. Matsumoto, and M. Kitazawa, "Rain-wind excitation of cables on cable- stayed Higashi-Kobe bridge and cable vibration control," in Proceedings of the International Conference on Cable-Stayed and Suspension Bridges, pp. 507-514, AFPC, Deauville, France, 1994. 


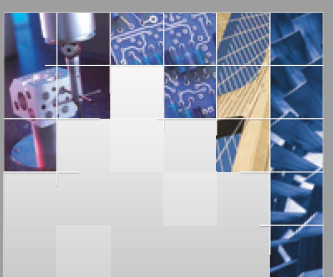

\section{Enfincering}
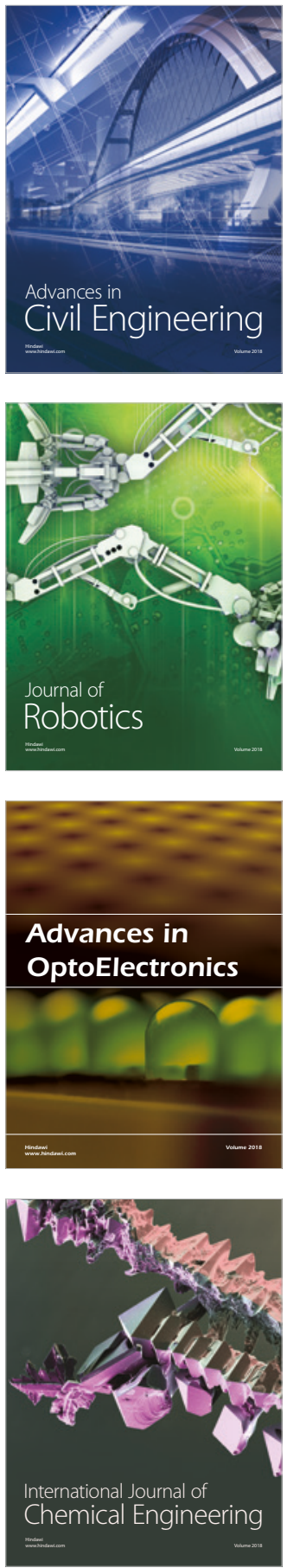

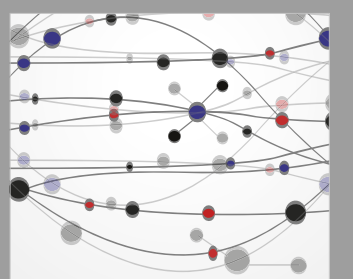

\section{Rotating \\ Machinery}

The Scientific World Journal

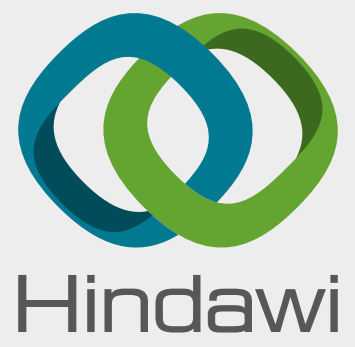

Submit your manuscripts at

www.hindawi.com
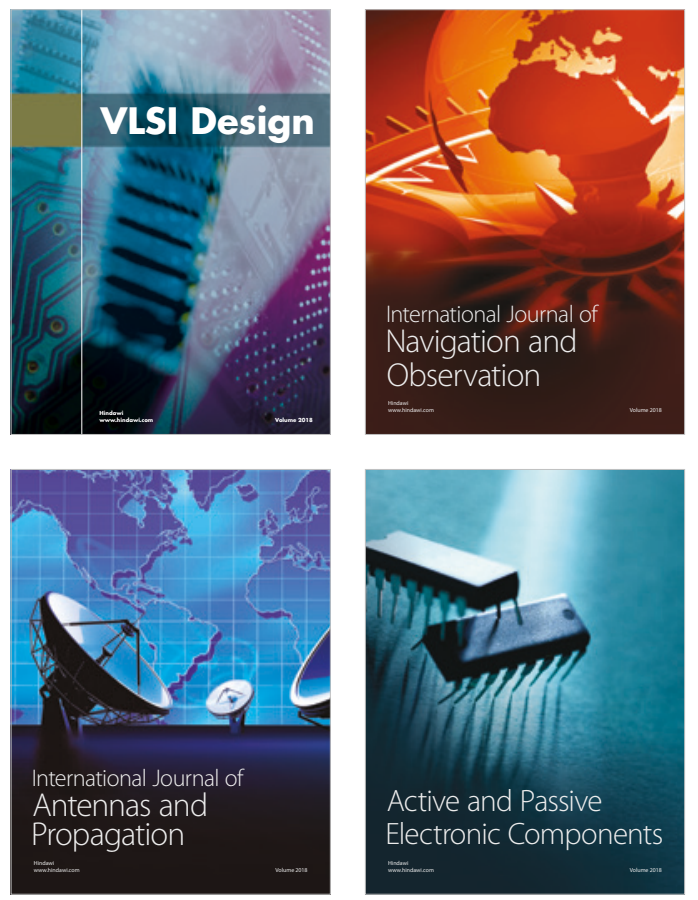
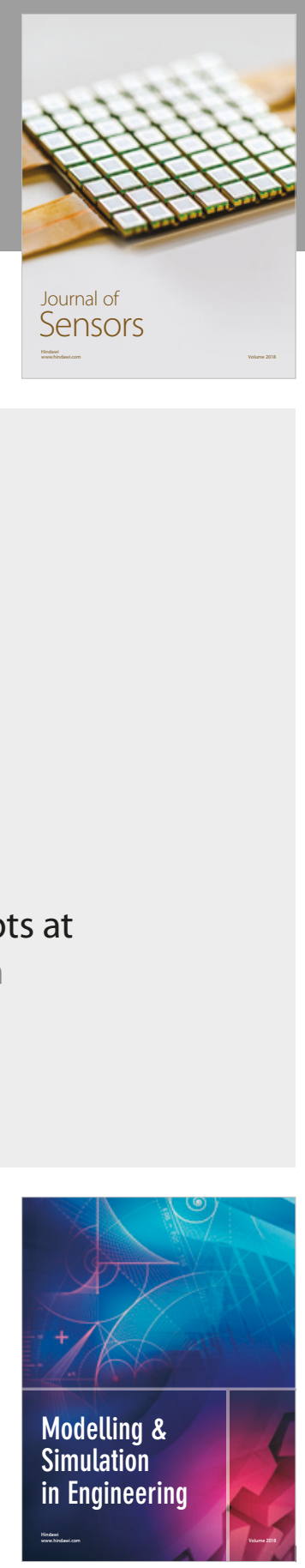

\section{Advances \\ Multimedia}
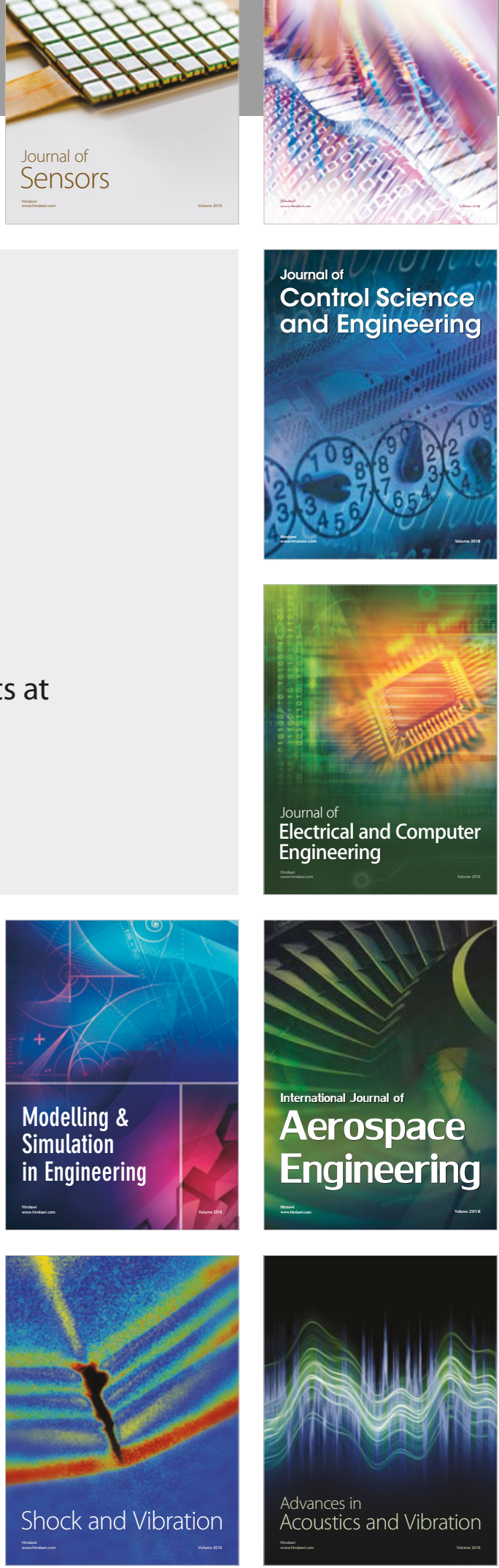